\title{
Tratamento cirúrgico de fibroma ossificante juvenil psamomatoide: relato de caso clínico
}

Surgical treatment of juvenile psammomatoid ossifying fibroma: a case report

Tratamiento quirúrgico del fibroma osificante juvenil psamomatoide: reporte de caso

Leticia Thais OTAVIANO ${ }^{1}$

Cristian STATKIEVICZ2

Christopher Henrique GIBIM²

Denise da Rosa FURTADO²

Ricardo Alves MATHEUS 2

Cecilia Luiz PEREIRA STABILE ${ }^{2}$

Glaykon Alex Vitti STABILE2

${ }^{I}$ Graduada, Curso de Odontologia, Universidade Estadual de Londrina (UEL) 86057-970 Londrina - PR, Brasil

${ }^{2}$ Área de Cirurgia Bucal, Departamento de Medicina Oral e Odontologia Infantil, Universidade Estadual de Londrina (UEL) 86057-970 Londrina-PR, Brasil

\begin{abstract}
Resumo
Introdução: O fibroma ossificante juvenil psamomatoide é um neoplasma de tecido conjuntivo fibroso celularizado, tipicamente não encapsulados de limites bem definidos, de crescimento rápido e assintomático, acometendo principalmente maxila de pacientes jovens. O diagnóstico geralmente acontece pela observação clínica da expansão cortical e deformidade facial evidente. Radiograficamente apresentamse como lesões radiolúcidas circunscritas, com possíveis áreas radiopacas centrais. O tratamento cirúrgico através da excisão cirúrgica e curetagem parece ser o mais adequado em vista da agressividade expansiva da lesão e da baixa taxa de recidiva. Objetivo: O objetivo desse trabalho é relatar o tratamento cirúrgico de um paciente do gênero masculino, jovem, diagnosticado com fibroma ossificante juvenil psamomatoide de grande dimensões em seio maxilar esquerdo. Caso clínico: Clinicamente assintomático, com expansão da cortical óssea em fundo de sulco maxilar esquerdo, divergência de raízes dentárias, estreitamento da fossa nasal e deformidade facial esquerda, o exame radiográfico panorâmico evidenciava lesão radiolúcida circunscrita com áreas radiopacas. O tratamento de escolha foi a excisão cirúrgica completa da lesão através do acesso único de Weber-Ferguson para prover adequado acesso a todas as regiões envolvidas e manutenção da morfologia da face por meio de reconstrução com malha de titânio. Este relato de caso ilustra a conduta frente a fibroma ossificante juvenil psamomatoíde de grande proporção. Conclusão: Apesar do acesso cirúrgico eleito, a estética facial foi pouco comprometida, a malha de titânio proveu manutenção apreciável do tecido mole e a área operada encontra-se em acompanhamento pós-operatório para eventual futura reconstrução.
\end{abstract}

Descritores: Fibroma Ossificante; Neoplasias de Tecido Ósseo; Cirurgia Bucal.

\begin{abstract}
Introduction: The psammomatoid juvenile ossifying fibroma is a neoplasm of cellular fibrous connective tissue, typically unencapsulated of well-defined limits, fast growing and asymptomatic, mainly affecting the maxilla of young patients. The diagnosis usually occurs through clinical observation of cortical expansion and evident facial deformity. Radiographically they present as circumscribed radiolucent lesions, with possible central radiopaque areas. The surgical treatment through surgical excision and curettage seems to be the most adequate in view of the expansive aggression of the lesion and the low relapse rate. Objective: The objective of this study is to report the surgical treatment of a young male patient, diagnosed with juvenile ossifying fibroma psammomatoid of large dimensions in the left maxillary sinus. Case Report: Clinically asymptomatic, with expansion of the cortical bone in the left maxillary groove, divergence of dental roots, narrowing of the nasal fossa and left facial deformity, the panoramic radiographic examination showed radiolucent lesion circumscribed with radiopaque areas. The treatment of choice was complete surgical excision of the lesion through Weber-Ferguson's unique access to provide adequate access to all involved regions and maintenance of face morphology through titanium mesh reconstruction. This case report illustrates the conduct of juvenile psammomatoid ossifying fibroma of great proportion. Conclusion: Despite the elective surgical access, the facial aesthetics was little compromised, the titanium mesh provided considerable soft tissue maintenance and the lesion is in postoperative follow-up for eventual future reconstruction.
\end{abstract}

Descriptors: Fibroma, Ossifying; Neoplasms, Bone Tissue; Surgery, Oral.

\section{Resumen}

Introducción: El fibroma osificante juvenil psamomatoide es una neoplasia de tejido conectivo fibroso celularizado, típicamente no encapsulado con bordes bien definidos, de rápido crecimiento y asintomáticos, que afecta principalmente al maxilar de pacientes jóvenes. El diagnóstico generalmente se realiza mediante observación clínica de expansión cortical y deformidad facial manifiesta. Radiográficamente se presentan como lesiones radiolúcidas circunscritas, con posibles áreas radiopacas centrales. El tratamiento quirúrgico mediante escisión quirúrgica y legrado parece ser el más apropiado dada la agresividad expansiva de la lesión y la baja tasa de recurrencia. Objetivo: El objetivo de este trabajo es informar el tratamiento quirúrgico de un paciente masculino joven diagnosticado con fibroma osificante juvenil psamomatoide grande en el seno maxilar izquierdo. Caso Clínico: Clínicamente asintomático, con expansión cortical ósea en el fondo del surco maxilar izquierdo, divergencia de las raíces dentales, estrechamiento de la fosa nasal y deformidad facial izquierda, el examen radiográfico panorámico mostró una lesión radiotransparente circunscrita con áreas radioopacas. El tratamiento de elección fue la escisión quirúrgica completa de la lesión a través del acceso exclusivo de Weber-Ferguson para proporcionar un acceso adecuado a todas las regiones involucradas y el mantenimiento de la morfología facial a través de la reconstrucción con malla de titanio. Este informe de caso ilustra el manejo del fibroma osificante juvenil psamomátida a gran escala. Conclusíon: A pesar del acceso quirúrgico elegido, la estética facial se vio poco comprometida, la malla de titanio proporcionó un mantenimiento apreciable de los tejidos blandos y el área operada se encuentra en seguimiento postoperatorio para una posible reconstrucción futura.

Descriptores: Fibroma Osificante; Neoplasias de Tejido Óseo; Cirugía Bucal.

INTRODUÇÃO

As lesões fibro-ósseas benignas se caracterizam pela substituição do osso normal por tecido conjuntivo composto por colágeno, fibroblastos e materiais mineralizados semelhantes ao osso ou cemento ${ }^{1}$. Dentre as lesões fibro-ósseas destaca-se o fibroma ossificante (FO). Segundo a classificação da Organização Mundial da Saúde
(OMS), o FO pode ser classificado como fibroma ossificante juvenil trabecular (FOJT) ou psamomatoide (FOJP) dependendo da sua apresentação histológica².

Os achados clínicos são variados e dependem da localização da lesão. Quando em maxila pode incluir deslocamento dentário, proptose orbital, 
deformidade facial e obstrução nasal ${ }^{3}$. A radiografia mostra lesão bem demarcada com área de diferentes densidades. A quantidade de tecido calcificado produzido mostrará graus variáveis de radiolucência e radiopacidade. As radiografias podem mostrar o deslocamento e a reabsorção radicular, mesmo que raro $^{4}$.

O tratamento baseia-se na curetagem cirúrgica ou ressecção devido a elevada taxa de recidiva. Outra etapa importante dentro do planejamento operatório é a escolha de um acesso adequado, que permita a visualização e remoção completa da lesão, com preservação de estruturas anexas importantes como a órbita, fossa nasal, dentes e inervação, visto que a maior incidência dessa lesão acontece na região de terço médio da face, área com anatomia peculiar ${ }^{5,6}$.

Dentro desse contexto o objetivo deste trabalho é relatar um caso de um paciente jovem, masculino, diagnosticado com Fibroma Ossificante Juvenil Psamomatoide de grandes dimensões na região maxilar esquerda, tratado por meio de ressecção cirúrgica através do acesso cirúrgico de Weber-Ferguson associado à instalação de uma malha de titânio para sustentação dos tecidos.

\section{CASO CLÍNICO}

Paciente do sexo masculino, 16 anos de idade, feoderma, foi encaminhado ao serviço de Cirurgia e Traumatologia Buco-Maxilo-Facial da Universidade Estadual de Londrina (UEL) queixando-se de aumento de volume indolor em lado esquerdo da face há 2 anos. Além disso, havia relato de dificuldade respiratória e episódios de sangramento nasal. Ao exame clínico extrabucal, observou-se assimetria facial, principalmente em vista ínferosuperior (Figuras 1 e 2), aumento de volume em hemiface esquerda, em região de complexo zigomático (Figura 3).

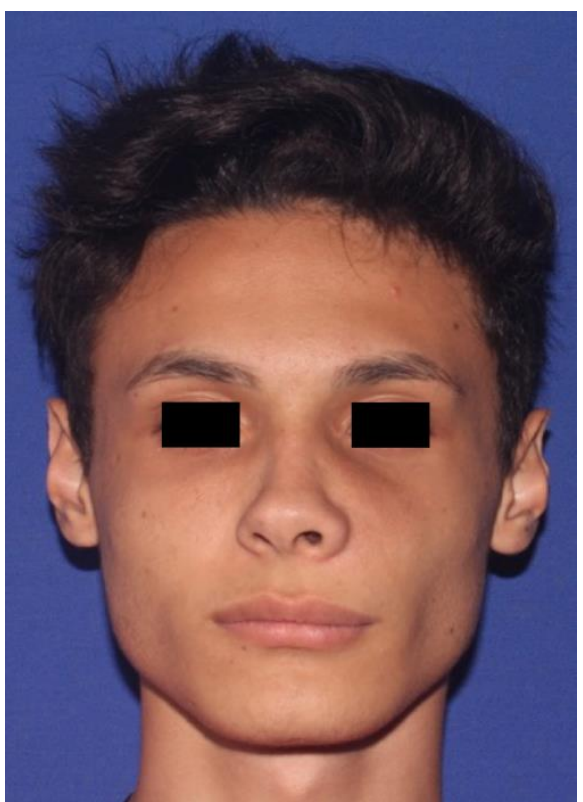

Figura 1: Fotografias clínicas evidenciando assimetria facial.

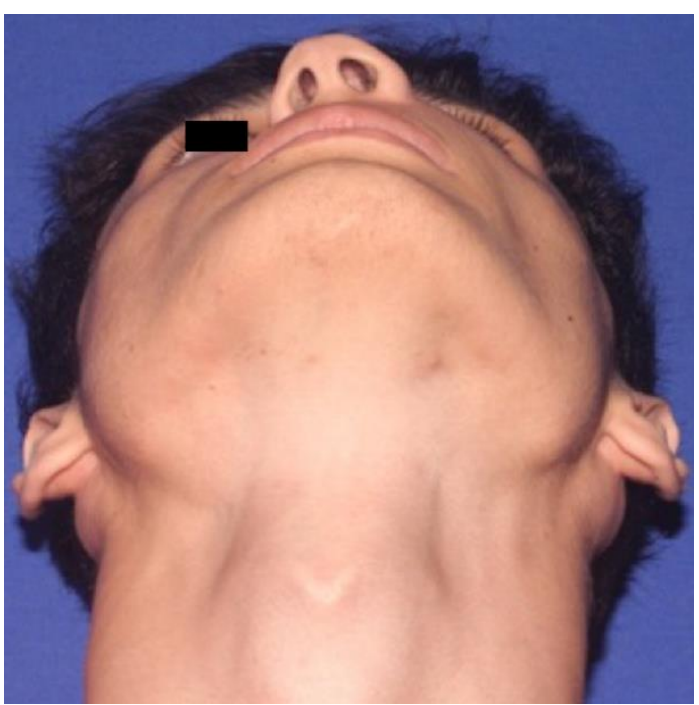

Figura 2: Vista ínferosuperior, evidenciando a assimetria facial.

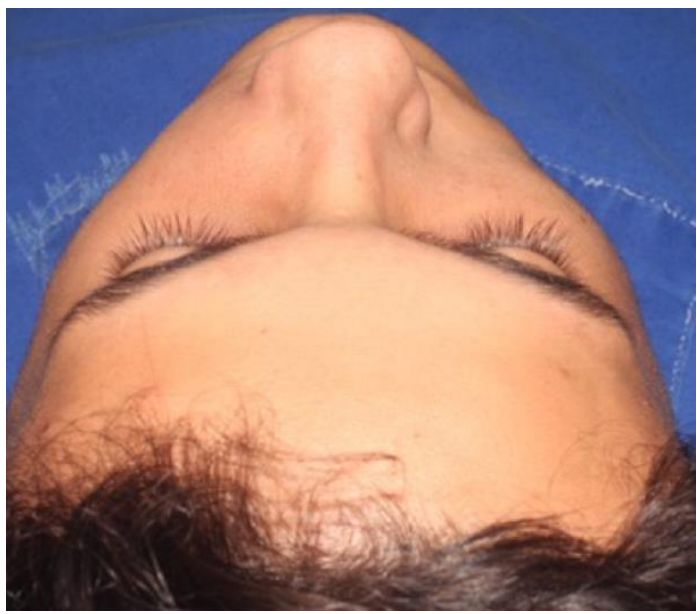

Figura 3 - Aumento de volume em hemiface esquerda.

Ao exame clínico intraoral, constatou-se expansão da cortical óssea em fundo de sulco maxilar esquerdo e vestibularização do elemento 22 (Figura 4), além do estreitamento da fossa nasal. Foram solicitados exames de imagem para auxílio no diagnóstico. A tomografia computadorizada revelou uma massa hiperdensa circunscrita com áreas hipodensas, em corte axial de aproximadamente 4,32 centímetros (Figura 5) e em corte coronal de aproximadamente 4,94 centímetros em seio maxilar esquerdo, envolvendo dentes e fossa nasal (Figura 6). E em uma ilustração em 3D, visualizou-se a divergência de raízes dentárias.

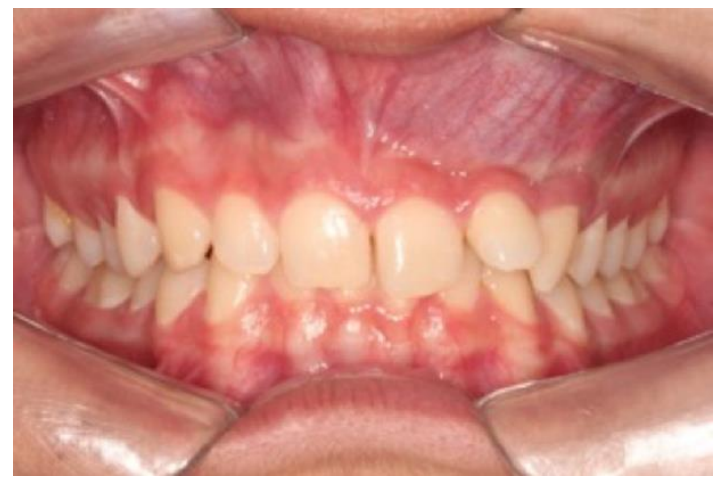

Figura 4: Aspecto intraoral, constatando-se expansão da cortical 
óssea em fundo de sulco maxilar esquerdo e vestibularização do incisivo lateral esquerdo.

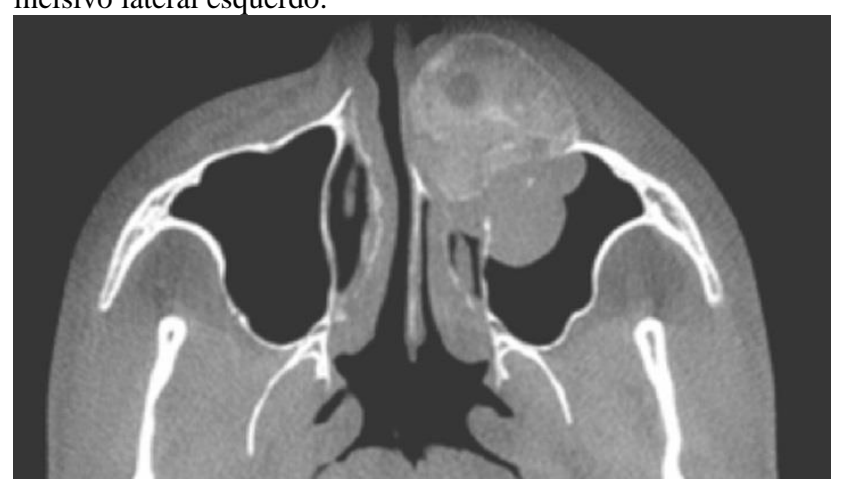

Figura 5: Tomografia computadorizada (Corte axial) relevando uma massa hiperdensa circunscrita com áreas hipodensas, de aproximadamente $4.32 \mathrm{~cm}$.

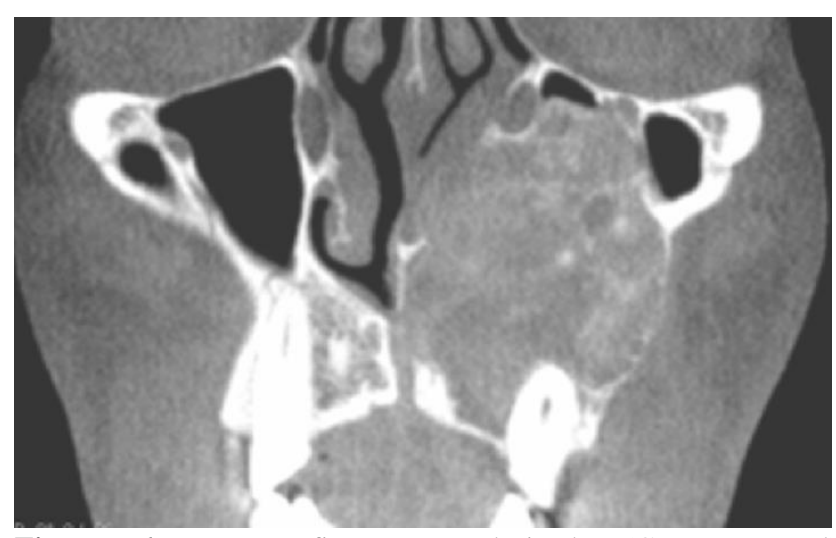

Figura 6: Tomografia computadorizada (Corte coronal) relevando massa de aproximadamente $4.94 \mathrm{~cm}$ em seio maxilar esquerdo, envolvendo dentes e fossa nasal.

De início, optou-se por realizar uma biópsia incisional, para elucidar o diagnóstico. $\mathrm{O}$ procedimento foi realizado em ambiente ambulatorial sob anestesia local (Figura 7). O exame histopatológico revelou uma proliferação de tecido conjuntivo fibroso celularizado denso com calcificações esferoidais psamomatoides, confirmando o diagnóstico de Fibroma ossificante juvenil psamomatoide (Figura 8). O tratamento de escolha foi a excisão cirúrgica completa da lesão através do acesso único de Weber-Ferguson (Figuras 9 e 10) para prover adequado acesso a todas as regiões envolvidas e manutenção da morfologia da face por meio de reconstrução com malha de titânio (Figura 11).

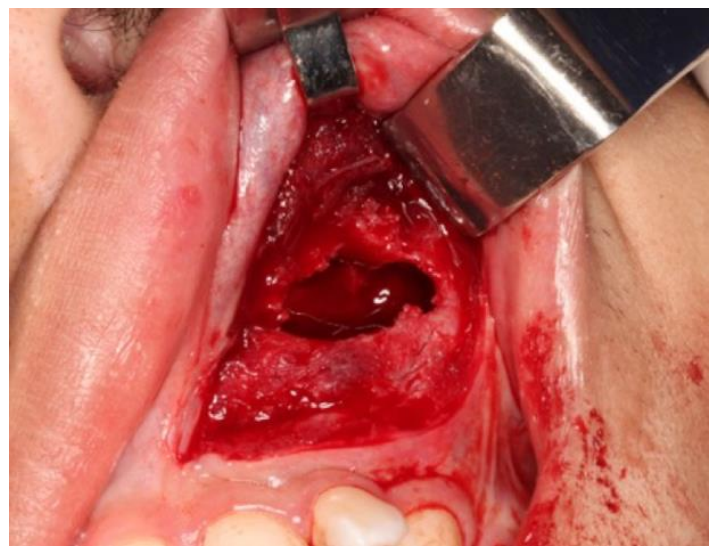

Figura 7: Biópsia incisional.

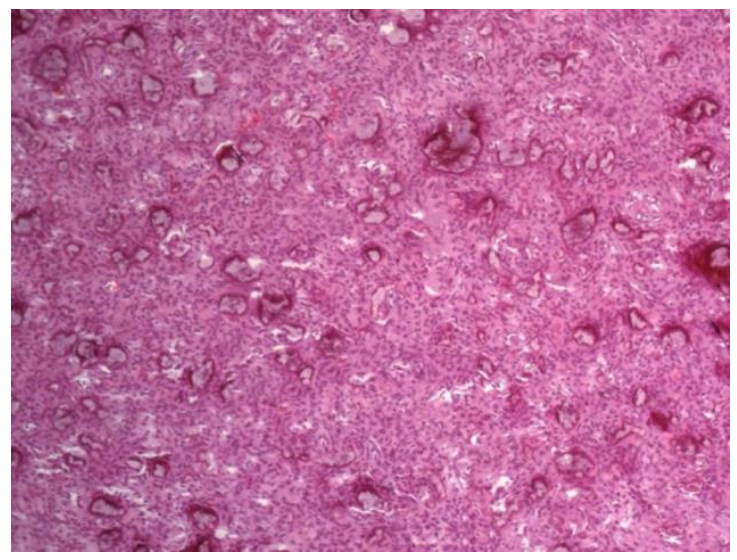

Figura 8: Características histopatológicas: proliferação de tecido conjuntivo fibroso celularizado denso com calcificações psamomatóides.

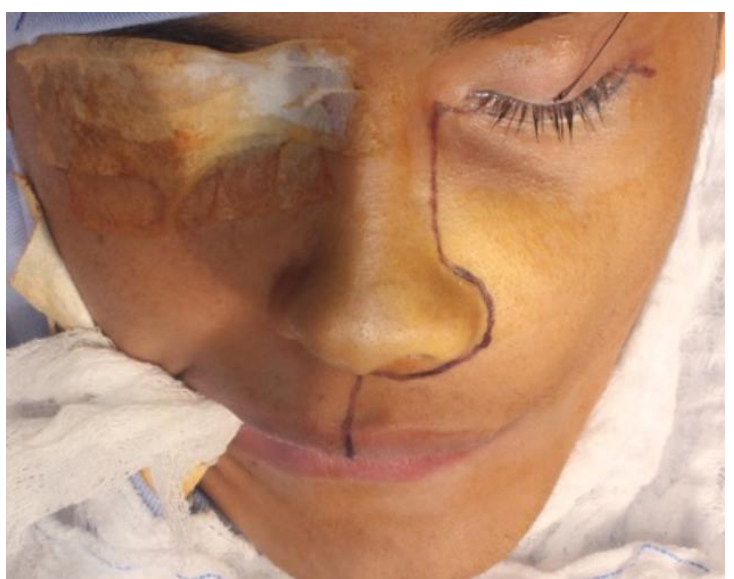

Figura 9 - Delimitação do acesso de Weber-Ferguson.

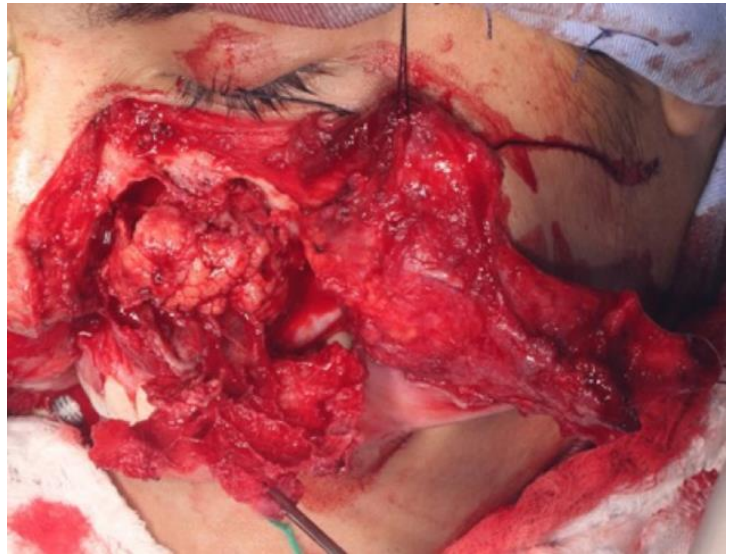

Figura 10: Remoção intraoperatória da lesão a qual demonstrava aspecto poroso e destacava-se facilmente das estruturas adjacentes.

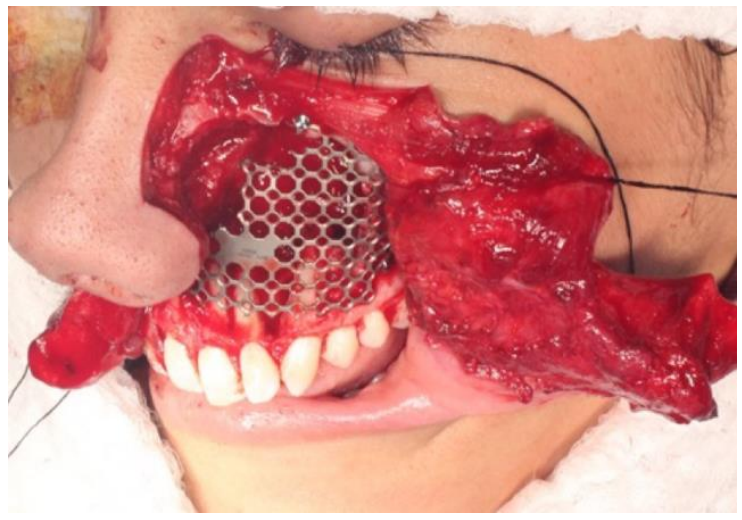

Figura 11: Fixação da malha de titânio. 
O paciente foi encaminhado então, ao centro cirúrgico do Hospital Universitário Regional do Norte do Paraná (HURNP) aos cuidados da equipe de Cirurgia e Traumatologia Buco-Maxilo-Facial (CTBMF) onde foi submetido a procedimento cirúrgico sob anestesia geral com intubação via orotraqueal. $\mathrm{O}$ material coletado foi encaminhado para análise anatomopatológica que confirmou $o$ diagnóstico de fibroma ossificante juvenil psamomatoide. A abordagem pelo acesso de WeberFerguson foi em virtude da extensão, agressividade, localização e proporção, possibilitando a exérese total da lesão. $\mathrm{O}$ paciente evoluiu sem intercorrências no pós-operatório e encontra-se em acompanhamento há 1 ano, observando ausência de sinais clínicos de recorrência da lesão nos exames imaginológicos póscirúrgicos (Figuras 12 e 13), bem como um resultado estético satisfatório (Figuras 14 e 15).

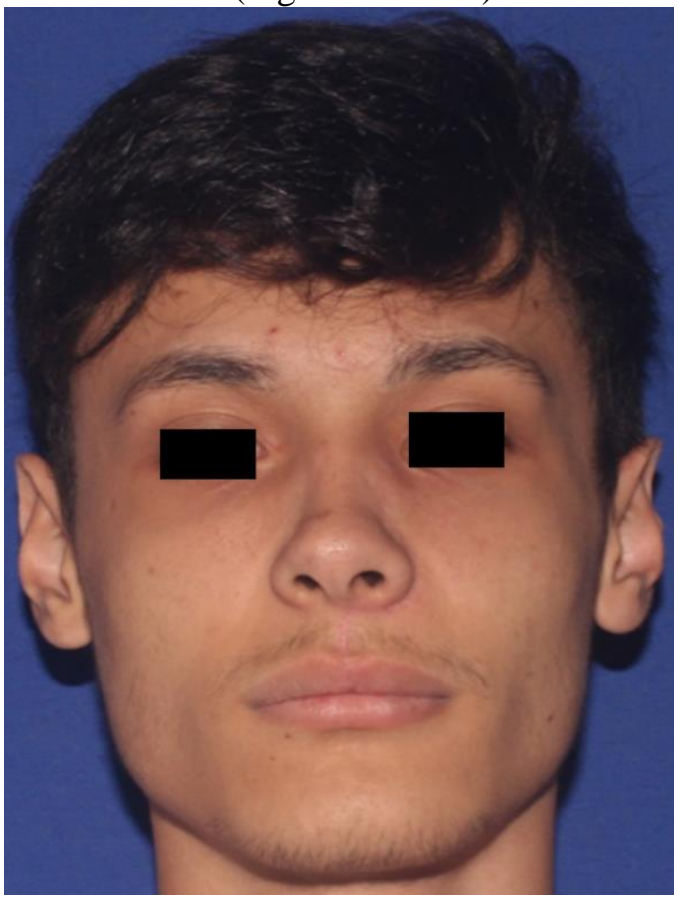

Figura 12: Fotografia pós-operatória apresentando resultado estético satisfatório.

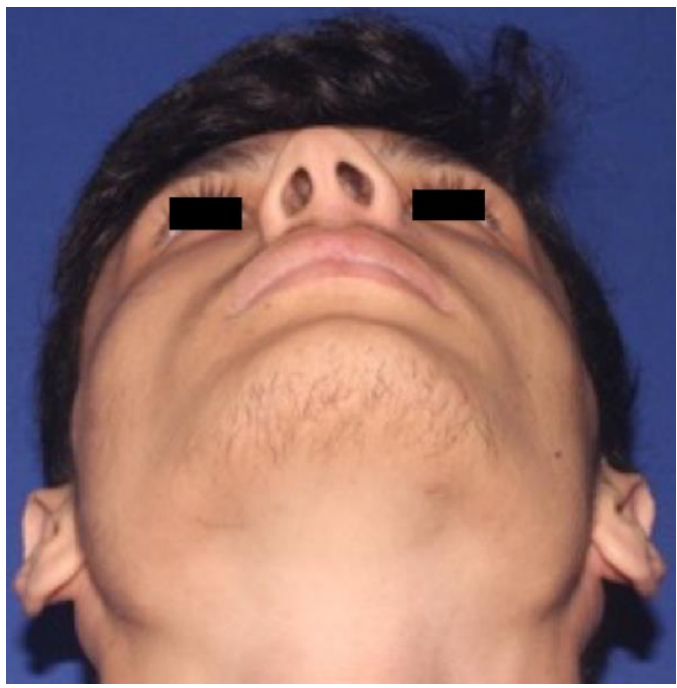

Figura 13: Vista ínferosuperior mostrando simetria no acompanhamento pós-operatório de 1 ano.

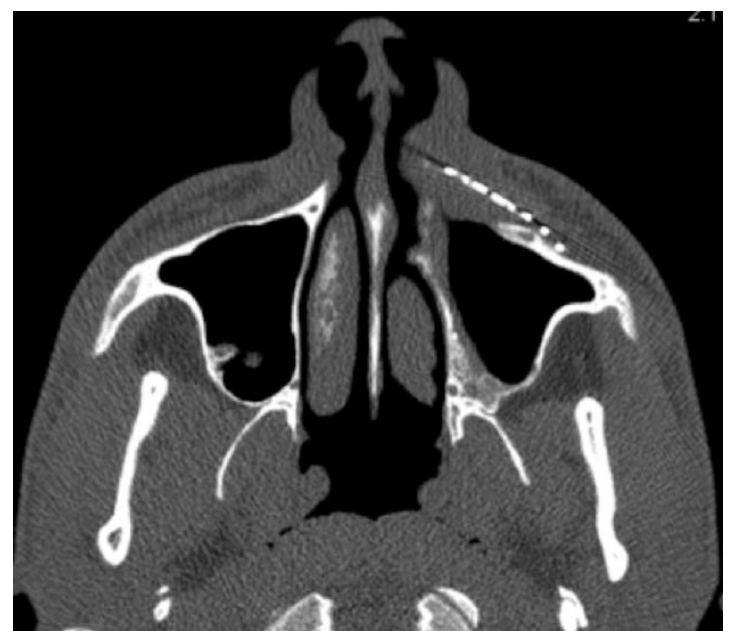

Figura 14: Tomografia computadorizada evidenciando seio maxilar livre e conformação da malha de titânio colocada no zigoma. 6 meses de acompanhamento.

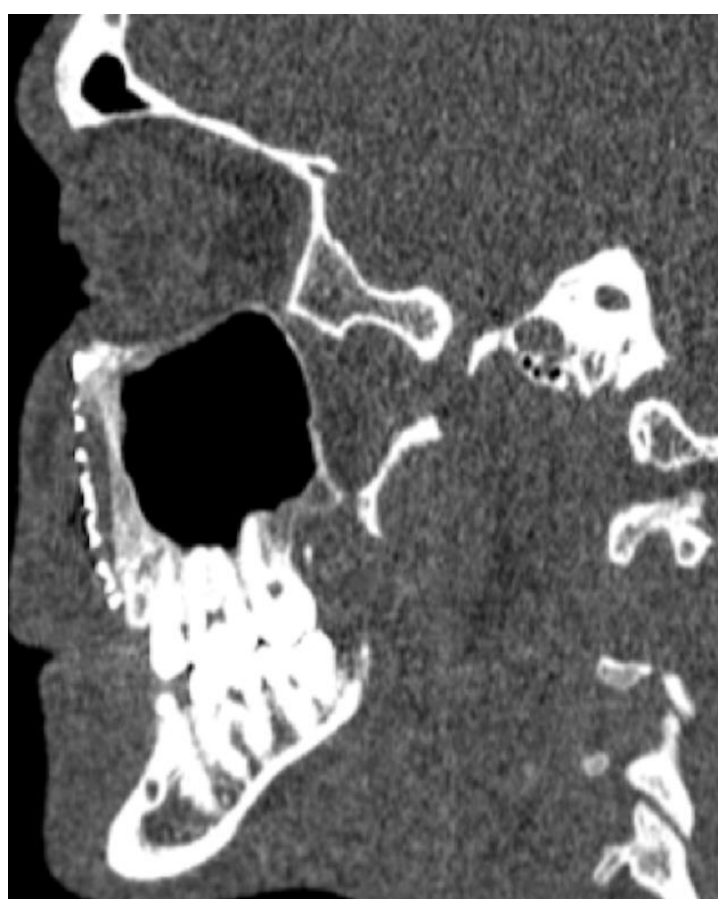

Figura 15: Tomografia computadorizada (corte sagital) não demonstrando sinais de recorrência da lesão.

\section{DISCUSSÃO}

$\mathrm{Na}$ literatura, os FOJs foram relatados nos ossos faciais (85\%), seguidos pelo crânio (12\%) e região mandibular $(10 \%)^{6}$. Dentro desse grupo a variante FOJP é mais frequente nas regiões sinonaso-orbitais e de crescimento rápido e agressivo. Embora ambos os padrões revelem características radiográficas e padrões de crescimento semelhantes, o tipo trabecular é geralmente diagnosticado em pacientes jovens ${ }^{7}$.

Nesse relato, o paciente apresentava sinais clínicos em regiões geralmente acometidas pelo FOJ descritas na literatura. $O$ envolvimento do seio maxilar nesse caso foi total, com invasão da fossa nasal, deslocamento de raízes dentárias, juntamente com o achado tomográfico nos levou a levantar a hipótese de FOJ, tal suspeita baseou-se em 
publicações anteriores que descreviam os aspectos clínico-radiográficos da lesão, onde os seios etmoidais são mais comumente envolvidos, seguidos pelos seios frontal, maxilar e esfenóide ${ }^{1,8,9}$. No entanto Toro et al. ${ }^{10}$, Leimola-Virtanen et al. ${ }^{11} \mathrm{e}$ Papadaki et al. ${ }^{12}$, concordaram que o FOJ não tem aspectos radiográficos específicos, sendo possivelmente uniloculares ou multilocular ${ }^{10-12}$.

Os mesmos autores relatam que o exame de imagem possibilita diferenciar o FOJ de displasia fibrosa, já que a displasia fibrosa geralmente não é cercada por uma cápsula fibrosa. A ressonância magnética mostra grande especificidade quando existe um envolvimento neurovascular e ocular específico. $\mathrm{O}$ diagnóstico acontece após a correta correlação entre achados clínicos, imaginológicos e histopatológicos ${ }^{4}$. Dessa mesma forma, observamos nesse relato que o exame tomográfico nos mostra uma lesão delimitada associada, com áreas hipo e hiperdensas entremeadas, isso associado ao aspecto clínico cirúrgico da lesão constatamos a presença de uma cápsula em toda a lesão, reforçando o que foi descrito por Figueiredo et al. ${ }^{4}$.

Cirurgicamente, houve uma facilidade na remoção completa da lesão devido a presença dessa cápsula citada anteriormente, outro aspecto importante sobre os limites definidos da lesão ajudam a diferenciar os FOJ dos sarcomas agressivos e carcinomas. Segundo Agarwal et al. ${ }^{5}$ o FOJ deve ser completamente enucleado do osso circundante devido a altas chances de recorrência. Observando a complexidade da região sino-naso-orbital, devemos levar em consideração que a possibilidade de recidiva poderia ser desastrosa para o paciente, podendo acarretar a perda parcial da maxila, dentes e até mesmo o assoalho orbital gerando grande morbidade do ponto de vista ocular. Sendo assim optamos pela cuidadosa exérese total da lesão.

De acordo com a literatura, uma abordagem adequada que permita a delimitação total da lesão é ideal, permitindo ao cirurgião uma ampla visualização de toda área a ser removida e solucionar qualquer complicação cirúrgica, ${ }^{8,9,13,14}$. Decidimos realizar a abordagem de Weber-Fergusson por conta da exposição adequada de maxila, cavidade nasal e órbita. A cicatriz resultante não ficou muito evidente, pois coincide com as linhas de tensão e as linhas finas do rosto do paciente.

A excisão total com margens seguras é o tratamento para lesões agressivas. Quando a remoção cirúrgica falha, observa-se uma alta taxa de recidiva, geralmente no pós-operatório imediato $\mathrm{e}$ frequentemente, mais agressiva que a primeira lesão ${ }^{15}$. No presente caso, optamos pela enucleação e curetagem ao invés de uma ressecção total, devido a presença de osso sadio em maxila, bem como a idade do paciente, que era jovem. Slootweg et al. ${ }^{16}$ relataram que não houve diferença entre pacientes que foram tratados com uma abordagem radical ou um mais conservador ${ }^{16}$.

A literatura mostra que a reconstrução tardia apresenta melhores resultados, porém a reconstrução imediata tem sido cada vez mais aceita ${ }^{17}$. No entanto, preferimos realizar uma adaptação de malha de titânio para sustentação dos tecidos moles devido ao amplo defeito criado pela lesão, onde a mesma foi fixada com parafusos monocorticais para estabilização permitindo o suporte tecidual. Optou-se por não realizar enxerto ósseo no primeiro momento, pois, mesmo que curetada toda a lesão o paciente apresenta risco de recidiva pela própria característica do tumor. E também, em nosso caso, apesar de o paciente ter perdido o pilar canino e parte do pilar zigomático maxilar, áreas de eventual reconstrução, o paciente não apresentava mobilidade ou instabilidade da maxila.

Reddy et al. ${ }^{15}$ relatam que a taxa de recidiva desses tumores é alta, e que necessitam de acompanhamento a longo prazo. Recorrências são observadas em um período que varia de 6 meses a 19 $\operatorname{anos}^{15}$. Nosso paciente está em acompanhamento clínico e tomográfico de 12 meses. No exame de imagem de controle, apresenta um envolvimento da malha por tecido mole, sem sinais de recidiva da lesão, os dentes envolvidos não apresentaram vitalidade pulpar, sendo encaminhado para avaliação endodôntica dos mesmos e o paciente refere estar satisfeito com o tratamento executado.

\section{CONCLUSÃO}

O FOJP é uma lesão com alto índice de recorrência e comportamento agressivo. A detecção precoce, o tratamento adequado e o acompanhamento em longo prazo são essenciais. A correlação de características clínicas, radiológicas e histopatológicas é crucial para construção e confirmação do diagnóstico. Apesar da extensa abordagem, o resultado estético foi favorável. Além disso, a malha de titânio proveu a manutenção apreciável dos tecidos moles. O paciente continuará em acompanhamento caso necessite de uma eventual futura reconstrução.

\section{REFERÊNCIAS}

1. Figueiredo LM, de Oliveira TF, Paraguassú GM, de Hollanda Valente RO, da Costa WR, Sarmento VA. Psammomatoid juvenile ossifying fibroma: case study and a review. Oral Maxillofac Surg. 2014;18(1):87-93.

2. Speight PM, Takata T. New tumour entities in the 4th edition of the World Health Organization Classification of Head and Neck tumours: odontogenic and maxillofacial bone tumours. Virchows Arch. 2018;472(3):331-39.

3. Linhares P, Pires E, Carvalho B, Vaz R. Juvenile psammomatoid ossifying fibroma of the orbit and 
paranasal sinuses. A case report. Acta Neurochir (Wien). 2011;153(10):1983-88.

4. Figueiredo LMG, Valente ROH, Sarmento VA, Trindade SC, Oliveira TFL, Costa WRM. Aspectos atuais no diagnóstico e tratamento do fibroma ossificante juvenil. Rev bras cir cabeça pescoço. 2012;41(2):99-102.

5. Agarwal SP, Kumar S, Singh HP, Usmani SA. Huge ossifying fibroma maxilla. Natl J Maxillofac Surg. 2015;6(2):241-43.

6. Neville BW, Damm DD, Allen CM, Bouquot JE. Patologia oral e maxilofacial. 3.ed. Rio de Janeiro: Elsevier; 2009.

7. El-Mofty S. Psammomatoid and trabecular juvenile ossifying fibroma of the craniofacial skeleton: two distinct clinicopathologic entities. Oral Surg Oral Med Oral Pathol Oral Radiol Endod. 2002;93(3):296-304.

8. Nogueira RLM, Nonaka CFW, Cavalcante RB, Carvalho AC, Souza LB. Fibroma ossificante juvenil localizado em mandíbula: relato de caso e breve revisão da literatura. Rev cir traumatol buco-maxilo-fac. 2009; 9(1):25-32.

9. Ranganath K, Kamath SM, Munoyath SK, Nandini HV. Juvenile psammomatoid ossifying fibroma of maxillary sinus: case report with review of literature. J Maxillofac Oral Surg. 2014;13(2):109-14.

10. Toro C, Millesi W, Zerman N, Robiony M, Politi M. A case of aggressive ossifying fibroma with massive involvement in the mandible: differential diagnosis and management options. Int $\mathrm{J}$ Pediatr Otorhinolaryngol. 2006 Extra 1:167-72.

11. Leimola-Virtanen $R$, Vähätalo $K$, Syrjänen $S$. Juvenile active ossifying fibroma of the mandible: a report of 2 cases. J Oral Maxillofac Surg. 2001;59(4):439-44.

12. Papadaki ME, Troulis MJ, Kaban LB. Advances in diagnosis and management of fibro-osseous lesions. Oral Maxillofac Surg Clin North Am. 2005;17(4):415-34.

13. Santos JN, Vieira TSLS, Góis Filho DM, Vasconcelos SJA, Azevedo RA. Displasia fibrosa: osteoplastia com acesso Weber-Ferguson. Relato de caso. Rev cir traumatol buco-maxilo-fac. 2010;10(1):73-80.

14. Melo RB, Silva PF, Gonçalves FLN, Rodrigues AL, Pontes HAR. Tratamento cirúrgico de granuloma central de células gigantes agressivo em maxila com acesso Weber Ferguson: Relato de caso. Rev cir traumatol buco-maxilo-fac. 2014; 14(4):65-70.

15. Reddy AV, Reddy KR, Prakash AR, Rajinikanth, Vidhyadhari P. Juvenile ossifying fibroma with aneurysamal bone cyst: a case report. J Clin Diagn Res. 2014;8(10):ZD01-ZD2.
16. Slootweg PJ, Müller H. Juvenile ossifying fibroma. Report of four cases. J Craniomaxillofac Surg. 1990;18(3):125-29.

17. Chiavaioli GMO. Fibroma ossificante juvenil em mandíbula: Relato de caso [monografia]. Belo Horizonte: Faculdade de Odontologia da Universidade Federal de Minas Gerais; 2015.

\section{CONFLITO DE INTERESSES}

Os autores declaram não haver conflitos de interesse.

\section{AUTOR PARA CORRESPONDÊNCIA}

\section{Cristian Statkievicz}

c.statkievicz@gmail.com

Rodovia Celso Garcia Cid - Pr 445 Km 380 Cx. Postal 10.011 - Campus Universitário, PR, 86057-970. Clínica Odontológica Universitária da Universidade Estadual de Londrina
Submetido em 09/09/2019

Aceito em 06/08/2020 